\title{
Properties of Avermectin Delivery System Using Surfactant-Modified Mesoporous Activated Carbon as a Carrier
}

\author{
Changjiao Sun $\left(\mathbb{D},{ }^{1,2}\right.$ Yan Wang, ${ }^{1}$ Xiang Zhao, ${ }^{1}$ Zhanghua Zeng, ${ }^{1}$ Bo Cui, ${ }^{1}$ \\ Yue Shen, ${ }^{1}$ Fei Gao, ${ }^{1}$ and Haixin Cui ${ }^{1}{ }^{1}$ \\ ${ }^{1}$ Institute of Environment and Sustainable Development in Agriculture, Chinese Academy of Agricultural Sciences, \\ No. 12 South Street of Zhongguancun, Haidian District, Beijing 100081, China \\ ${ }^{2}$ Gembloux Agro-Bio Tech, University of Liège, Passage des Déportés, 2, Gembloux, Belgium
}

Correspondence should be addressed to Haixin Cui; cuihaixin@caas.cn

Received 23 August 2017; Accepted 28 December 2017; Published 31 January 2018

Academic Editor: Miguel A. Garcia

Copyright (C) 2018 Changjiao Sun et al. This is an open access article distributed under the Creative Commons Attribution License, which permits unrestricted use, distribution, and reproduction in any medium, provided the original work is properly cited.

The sensitivity of avermectin to several environmental factors, especially light, causes low pesticidal activity and environmental pollution. In this study, surfactant-modified mesoporous activated carbon (MAC) was employed to absorb avermectin (Av) in order to improve its photostability and allow for sustained release of avermectin. The results suggest that sodium dodecyl sulfate (SDS) modified MAC has excellent absorption of avermectin, and the absorption can be represented by the Langmuir isotherm model. The Av-MAC-SDS delivery system significantly improves sustained release of avermectin and also effectively inhibits the photodegradation of avermectin. These results indicate that SDS-modified MAC can be used as a carrier for avermectin to improve its pesticidal activity and reduce pesticide residues.

\section{Introduction}

Pesticides are indispensable in agricultural production. Environmental pollution caused by the misuse of chemical pesticides, however, is becoming more and more serious $[1,2]$. Because of this, biopesticides have attracted increasing attention for their high bioefficiency, safety, and other environmentally friendly traits that are consistent with the requirements of sustainable agriculture [3]. Avermectin is a class of macrocyclic lactones isolated from the soil organism Streptomyces avermitilis. It has excellent pesticidal activity in agricultural systems due to high efficiency, low toxicity, and high selectivity. However, its conventional formulations still have some shortcomings, such as environmental sensitivity and short duration of effect. In order to improve the pesticidal activity of avermectin, it is preferable to adsorb avermectin onto some forms of adsorbent that can prevent degradation and consequently avoid the loss of pesticidal activity.

Activated carbon is an adsorbent material with a large surface area. Because of its well-developed pore structure and chemical stability, it has been widely used for purification, especially for purifying air and water $[4,5]$. In the last decade, it has been extensively used for the prevention of environmental pollution [6-8], and in pharmaceutical applications [9] and the catalytic industry [10] as well. As a carrier of chemical pesticides, activated carbon protects the active ingredients and allows for sustained release of the active ingredients [11]. However, research about mesoporous activated carbon (MAC) loaded with biopesticides has been limited. Our previous work shows that MAC allowed for sustained release and UV-shielding of avermectin [12], and the surface acidic groups of MAC, especially carboxyl groups, showed a significant negative correlation with adsorption of avermectin [13].

In this study, MAC with a Brunauer-Emmett-Teller (BET) surface area greater than $1200 \mathrm{~m}^{2} / \mathrm{g}$ was modified with surfactants. The BET surface area of MAC before and after modification was tested using a surface area analyzer. The avermectin loading capacity of modified MAC was compared with other conventional pesticide carriers by analyzing 
the absorption of avermectin from a methanol solution. Avermectin adsorption data were also modeled using both Langmuir and Freundlich classical adsorption isotherms. Finally, the sustained release properties and resistance to photodegradation of the delivery system were analyzed and evaluated.

\section{Materials and Methods}

2.1. Materials. Avermectin was purchased from Qilu Pharmaceutical Co., Ltd. (Inner Mongolia, China). Mesoporous activated carbon and bentonite were obtained from SigmaAldrich Shanghai Trading Co., Ltd. (Shanghai, China). Sodium dodecyl sulfate (SDS) and tetrabutylammonium bromide (TBAB) were purchased from J\&K Scientific Ltd. (Beijing, China). Kaolin and diatomite were obtained from Sinopharm Chemical Reagent Co., Ltd. (Shanghai, China). HPLC grade methanol was purchased from Thermo Fisher Scientific (Beijing, China). Other chemicals were purchased from the Beijing Chemical Factory, China. All chemicals were of analytical grade and were used as received. The water used in all analytical experiments was Milli-Q water $(18.2 \mathrm{M} \Omega \cdot \mathrm{cm}$, TOC $\leq 4 \mathrm{ppb}$ ) prepared using a Milli-Q Advantage A10 system (Millipore, Milford, MA, USA).

\subsection{Preparation of the Modified MAC with Different Surfac-} tants. MAC was first purified several times with ultrapure water to remove adsorbed impurities and metal ions. Then it was filtered and oven dried at $100^{\circ} \mathrm{C}$ for $10 \mathrm{~h}$. Five g of purified MAC was suspended in $500 \mathrm{~mL}$ of $10 \mathrm{mmol} / \mathrm{L}$ SDS and TBAB solution with stirring at $25^{\circ} \mathrm{C}$ for $10 \mathrm{~h}$. The mixture was filtered, thoroughly rinsed with ultrapure water to remove excess surfactant, and oven dried at $60^{\circ} \mathrm{C}$ for $8 \mathrm{~h}$.

2.3. Characterization of MAC. The Brunauer-Emmett-Teller (BET) measurements of MAC and pore structure analysis were conducted at $-196.15^{\circ} \mathrm{C}$ using a surface area analyzer (Tristar II 3020, Micromeritics Instrument Co., Norcross, GA, USA). The pore size distribution was calculated with the Barrett-Joyner-Halenda $(\mathrm{BJ} H)$ method. An elemental analyzer (EA2400, PerkinElmer Inc., Shelton, CT, USA) was used to examine changes in $\mathrm{C}, \mathrm{H}$, and $\mathrm{N}$ contents using the Pregl-Dumas Method before and after the modification.

2.4. Determination of Avermectin Content. The avermectin concentration of the suspension was determined by high performance liquid chromatography (HPLC) (Agilent 1260, Agilent Technologies, Ltd., Santa Clara, CA, USA) using a C18 column ( $5 \mathrm{um}, 4.6 \mathrm{~mm} \times 150 \mathrm{~mm}$, Agilent Technologies, Ltd., Santa Clara, CA, USA) at room temperature. The mobile phase was composed of methanol and water $(90: 10)$. The flow rate was $1.0 \mathrm{~mL} / \mathrm{min}$, and a UV detector wavelength of $245 \mathrm{~nm}$ was used. The initial concentration of avermectin standard solutions was $C_{0}(\mathrm{mg} / \mathrm{mL})$. Pesticide-loading capacity $\left(Q_{t}\right)$ was calculated according to the following formula:

$$
Q_{t}=\frac{\left(C_{0}-C_{t}\right) V}{m},
$$

where $V$ is the solution volume and $m$ is the mass of adsorbent.

2.5. Modeling of Adsorption Isotherms. Batch equilibrium studies were carried out by adding $200 \mathrm{mg}$ MAC-SDS into a series of $150 \mathrm{~mL}$ Erlenmeyer flasks with $40 \mathrm{~mL}$ of an avermectin methanol solution at different concentrations. The flasks were maintained at $25^{\circ} \mathrm{C}$ for $24 \mathrm{~h}$. After centrifuging at $10,000 \mathrm{rpm}$ for $10 \mathrm{~min}$, the equilibrium concentration of avermectin in the supernatant was determined by HPLC. The amount of adsorbed Av at equilibrium, $Q_{e}$, was calculated by

$$
Q_{e}=\frac{\left(C_{0}-C_{e}\right) V}{m}
$$

where $C_{0}$ and $C_{e}$ are the concentrations of avermectin at initial and equilibrium stages, respectively; $V$ is the volume of the suspension; and $m$ is the mass of MAC-SDS.

2.6. Investigation of Sustained Release Behaviors of Av-MAC$S D S$. The release profiles of avermectin from Av-MAC-SDS samples were investigated as follows: $100 \mathrm{mg}$ Av-MAC-SDS samples were suspended in $20 \mathrm{~mL}$ methanol. The suspension was transferred to a dialysis bag. After tightly sealing the dialysis bag it was put into $100 \mathrm{~mL}$ methanol as the release medium. The release rate of avermectin from the Av-MACSDS sample was calculated by measuring the concentrations of avermectin dissolved in the release medium at different times to evaluate the sustained release property. The concentrations of avermectin were measured using HPLC by collecting $1.0 \mathrm{~mL}$ of the release media outside of the dialysis bag at different intervals of $24,48,72,100,150,210$, and $260 \mathrm{~h}$. Free avermectin was used as a control.

2.7. Photolysis Experiments of Avermectin in Av-MAC-SDS. The photolytic behavior of avermectin in Av-MAC-SDS was evaluated by the thin-film method described in reference [14], with free avermectin as a control. Ten $\mathrm{mL}$ of the methanol suspension of Av-MAC-SDS was placed in several uncovered glass Petri dishes and dried in air at room temperature to form thin films. The glass Petri dishes with thin films were then placed in a Xenon-arc photostability test chamber (XT5409-XPC80, Xutemp Temptech Co. Ltd., Hangzhou, China), at a constant temperature of $25^{\circ} \mathrm{C}$. The Petri dishes were removed from the chamber after 24, 48, and $72 \mathrm{~h}$. Av-MAC-SDS was then recovered by rinsing the thin films with $5 \mathrm{~mL}$ methanol, followed by ultrasonic treatment for $10 \mathrm{~min}$. The suspension was centrifuged and the supernatant was collected and analyzed by HPLC to determine the remaining concentrations of avermectin. The degradation of free avermectin was performed under the same conditions.

\section{Results and Discussion}

3.1. Characterization of Modified MAC. Table 1 shows the BET surface area, total pore volume, and pore size of MAC before and after modification with the cationic surfactant TBAB and the anionic surfactant SDS. The modification did 
TABLE 1: BET surface area, total pore volume, and pore size of MAC and surfactant-modified MAC.

\begin{tabular}{lccc}
\hline Carrier & $\begin{array}{c}\text { BET surface area } \\
\mathrm{m}^{2} / \mathrm{g}\end{array}$ & $\begin{array}{c}\text { Total pore volume } \\
\mathrm{m}^{3} / \mathrm{g}\end{array}$ & $\begin{array}{c}\text { Pore size } \\
\mathrm{nm}\end{array}$ \\
\hline MAC & 1232.89 & 1.08 & 6.22 \\
MAC-SDS & 707.39 & 0.63 & 6.19 \\
MAC-TBAB & 831.40 & 0.65 & 6.10 \\
\hline
\end{tabular}

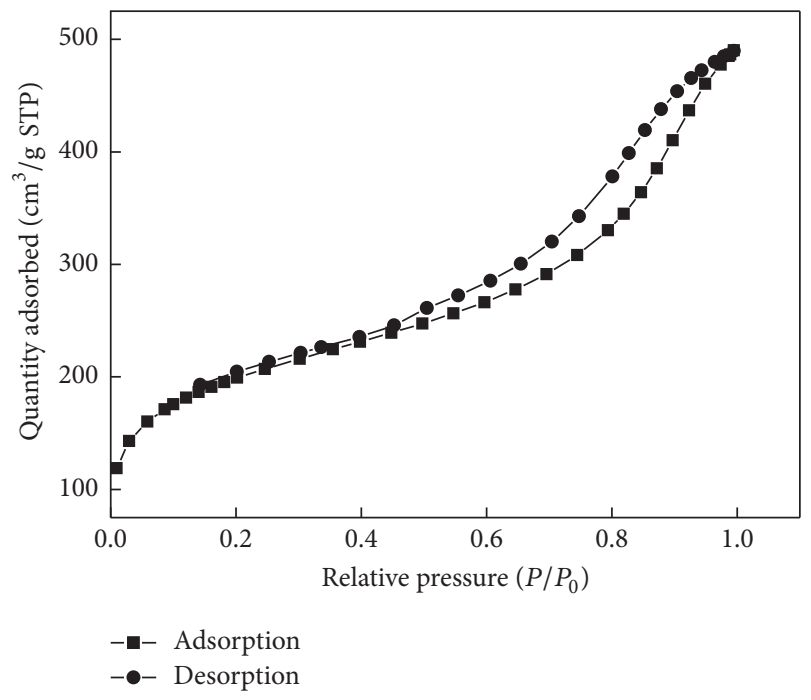

FIGURE 1: The nitrogen adsorption-desorption curves of MAC-SDS.

TABLE 2: Element contents of MAC and surfactant-modified MAC.

\begin{tabular}{lccc}
\hline Carrier & $\begin{array}{c}\text { C contents } \\
\%\end{array}$ & $\begin{array}{c}\text { H contents } \\
\%\end{array}$ & $\begin{array}{c}\text { N contents } \\
\%\end{array}$ \\
\hline MAC & 69.76 & 3.02 & 0.96 \\
MAC-SDS & 76.49 & 3.24 & 0.91 \\
MAC-TBAB & 78.07 & 3.33 & 1.14 \\
\hline
\end{tabular}

not cause significant changes in average pore size. According to the classification of the International Union of Pure and Applied Chemistry (IUPAC), the pores of adsorbents are grouped into micropore $(d<2 \mathrm{~nm})$, mesopore $(d=$ 2-50 nm), and macropore $(d>50 \mathrm{~nm})$ [15]. The average pore sizes of MAC before and after the modification were within the mesopore range of the IUPAC classification. The mesoporous structure of MAC-SDS can also be observed from the nitrogen adsorption and desorption isotherms [16] in Figure 1. Table 2 shows the $\mathrm{C}, \mathrm{H}$, and $\mathrm{N}$ contents of MAC before and after modification with surfactants. Compared with nonmodified MAC, the C content of modified MAC with surfactants dramatically increased, which indicated that the surfactants had been grafted onto the MAC.

3.2. Adsorption Capacity. The adsorption of MAC for avermectin in solution before and after modification was compared with other commonly used pesticide carriers (talc,
TABLE 3: The adsorption capacity for avermectin with different carriers.

\begin{tabular}{lc}
\hline Carriers & $\begin{array}{c}\text { Amount of adsorbed avermectin } \\
\mathrm{mg} / \mathrm{g}\end{array}$ \\
\hline MAC-SDS & 275.4 \\
MAC-TBAB & 204.4 \\
MAC & 156.7 \\
Talc & 36.6 \\
Bentonite & 35.4 \\
Kaolin & 30.7 \\
Diatomite & 4.7 \\
\hline
\end{tabular}

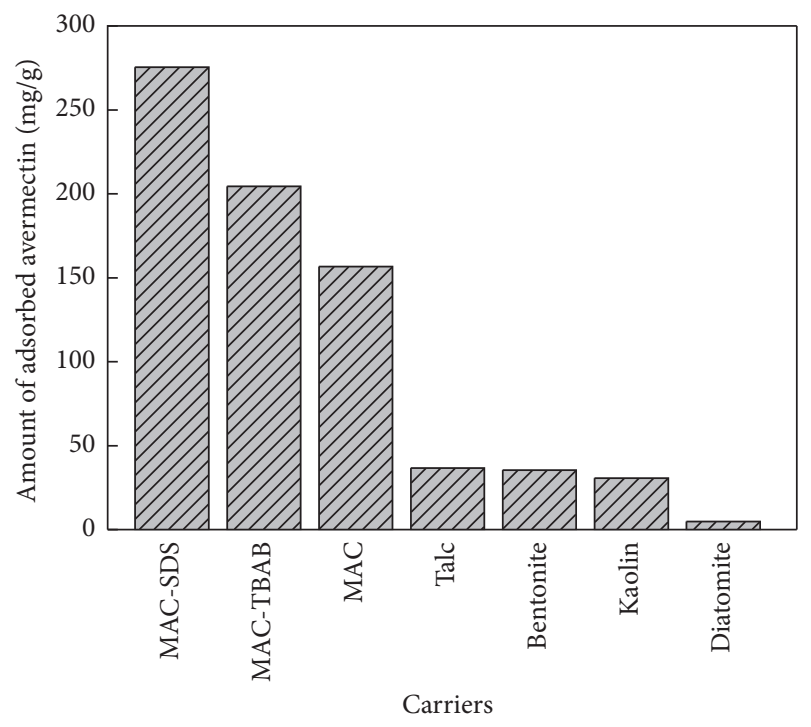

FIgURE 2: The adsorption capacity for avermectin with different carriers.

bentonite, kaolin, and diatomite). Batch studies were carried out by adding $200 \mathrm{mg}$ absorbents into a series of $150 \mathrm{~mL}$ Erlenmeyer flasks with $20 \mathrm{~mL}$ of $8 \mathrm{mg} / \mathrm{mL}$ avermectin methanol solution. As shown in Table 3 and Figure 2, because of the large special surface area and well-developed pore structure of MAC, the adsorption performance of MAC for avermectin was significantly better than talc, bentonite, kaolin, and diatomite. The adsorption capacity of MAC is mainly related to pore structures and surface chemical properties [17] and was improved after modification with surfactants. The nonpolar alkyl aliphatic chains of surfactants may enhance the adsorption of MAC for avermectin.

3.3. Adsorption Isotherms. The results obtained for the adsorption of avermectin were examined using Langmuir and Freundlich isotherm models [18-20]. The correlation coefficient $\left(R^{2}\right)$ was used to evaluate the adequateness of the different models to fit the adsorption process.

The Langmuir isotherm model, which is based on the assumption that the maximum adsorption corresponds to 


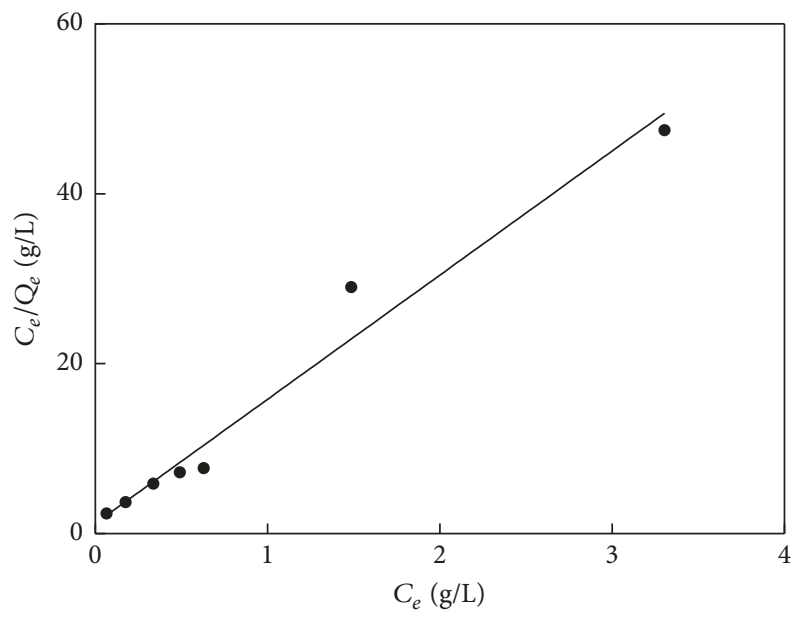

FIgURE 3: The Langmuir isotherm model of avermectin adsorbed by MAC-SDS.

a saturated monolayer of solute molecules on the adsorbent surface, with no lateral interaction between adsorbed molecules, is given by the following equation:

$$
\frac{C_{e}}{Q_{e}}=\frac{1}{Q_{0} b}+\frac{1}{Q_{0}} C_{e},
$$

where $Q_{e}(\mathrm{mg} / \mathrm{g})$ and $C_{e}(\mathrm{mg} / \mathrm{mL})$ represent the amount of adsorbed avermectin per unit mass of MAC-SDS and avermectin concentration at equilibrium, respectively; and $Q_{0}$ and $b$ refer to the Langmuir constants for MAC-SDS, which are related to the maximum avermectin adsorption capacity to form a complete monolayer on the surface of MAC-SDS and an affinity parameter, respectively.

The Freundlich model is an empirical equation based on adsorption on a heterogeneous surface. It is assumed that the most active sites are bound first and then the binding strength decreases with an increase in the number of sites bound. The Freundlich isotherm is depicted in the following equation:

$$
\ln Q_{e}=\ln K_{F}+\frac{1}{n} \ln C_{e},
$$

where $K_{F}$ and $n$ are the characteristic Freundlich constants that are related to adsorption capacity and intensity, respectively. These parameters can be obtained from the linear plot of $\ln Q_{e}$ versus $\ln C_{e}$, which has a slope of $1 / n$ and an intercept of $\ln K_{F}$.

The correlation coefficient obtained from the Langmuir model was found to be $R^{2}=0.9657$ for the adsorption of avermectin on MAC-SDS (Figure 3). For the Freundlich model, the $R^{2}$ was 0.5042 . These results indicate that the adsorption of avermectin on MAC-SDS can be represented by the Langmuir model.

3.4. Sustained Release Behaviors of Av-MAC-SDS. Figure 4 shows the release behaviors of free avermectin and avermectin from Av-MAC-SDS. Almost the entire amount of free avermectin had been released after $72 \mathrm{~h}$. Compared with free avermectin, the initial burst release of Av-MAC-SDS was not

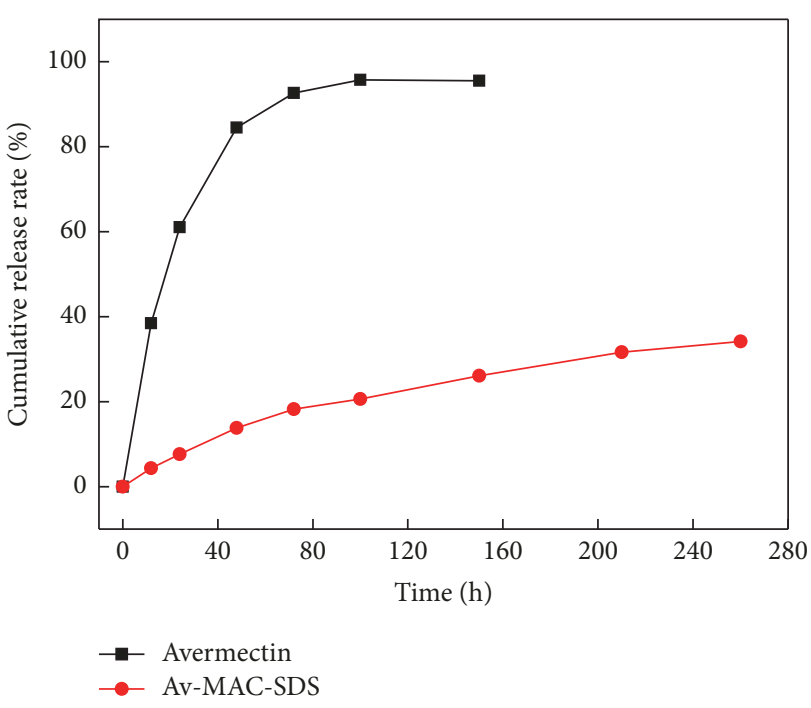

FIGURE 4: Release profile of avermectin loaded by Av-MAC-SDS.

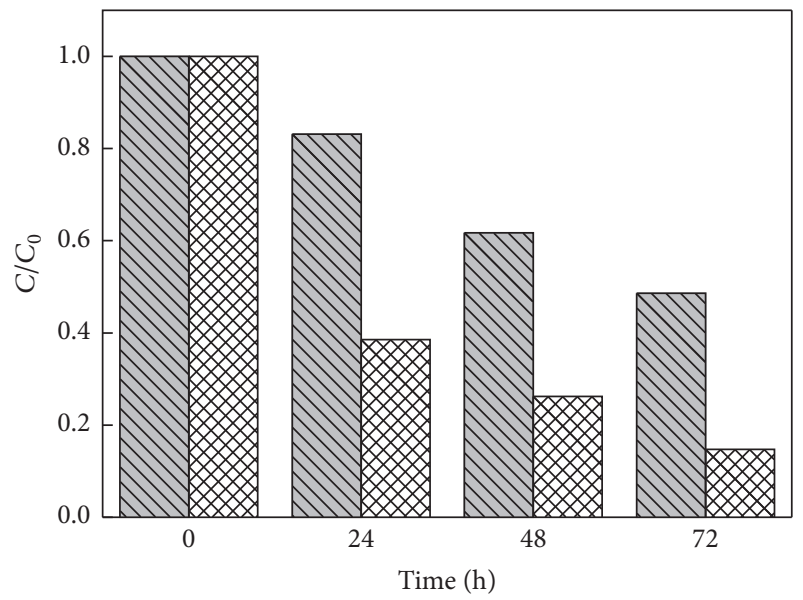

MIV Adsorbed avermectin

Free avermectin

FIGURE 5: Change in normalized concentration of free and adsorbed avermectin by Av-MAC-SDS to UV irradiation time.

obvious. As expected, Av-MAC-SDS exhibited slower release rates due to the rich pore structure, which slowed the release of avermectin. The release rate of Av-MAC-SDS was relatively fast at the initial stage and then gradually slowed down with increased time, as the avermectin adsorbed on the surface of Av-MAC-SDS was easier to release than the avermectin loaded within the carriers.

3.5. Effects of Av-MAC-SDS on Photodegradation of Avermectin. Figure 5 shows the changes of normalized concentrations of avermectin, which are the ratio of remaining concentrations to the initial concentrations of avermectin, under UV irradiation for $0,24,48$, and $72 \mathrm{~h}$ for Av-MAC-SDS and free avermectin, respectively. The photolytic rates of avermectin were $16.9 \%$ and $61.4 \%$, respectively, for Av-MAC-SDS 
and free avermectin after $24 \mathrm{~h}$, indicating that Av-MACSDS could protect avermectin from photodegradation. The photolytic rates reached $51.4 \%$ and $85.3 \%$, for Av-MAC-SDS and free avermectin, respectively, after $72 \mathrm{~h}$ of UV irradiation. The results further confirmed the capability of Av-MAC-SDS for protecting avermectin from photodegradation.

\section{Conclusion}

In summary, surfactant-modified MAC was employed as the carriers for avermectin. The average pore sizes of modified MAC were still within the mesopore range. The surfactantmodified MAC, especially the SDS-modified MAC, showed an excellent adsorption for avermectin. The adsorption equilibrium of avermectin by SDS-modified MAC could be fitted by the Langmuir isotherm model. In addition, the MAC-SDS delivery system could significantly improve sustained release of avermectin and also effectively inhibits the photodegradation of avermectin, which is favorable to overcome the environmental sensitivity of biopesticides and improve efficacy in crops protection.

\section{Abbreviations}

Av-MAC-SDS: Avermectin with sodium dodecyl sulfate modified mesoporous activated carbon

BET: Brunauer-Emmett-Teller

BJH: Barrett-Joyner-Halenda

HPLC: High performance liquid chromatography

IUPAC: International Union of Pure and Applied Chemistry

MAC: $\quad$ Mesoporous activated carbon

MAC-SDS: Sodium dodecyl sulfate modified mesoporous activated carbon

SDS:

TBAB: Sodium dodecyl sulfate Tetrabutylammonium bromide.

\section{Conflicts of Interest}

The authors declare no competing financial interest.

\section{Acknowledgments}

This research was supported by the Major National Scientific Research Program of China (2014CB932200) and the National Key Research and Development Program of China (2016YFD0200500).

\section{References}

[1] E. Morillo and J. Villaverde, "Advanced technologies for the remediation of pesticide-contaminated soils," Science of the Total Environment, vol. 586, pp. 576-597, 2017.

[2] J. J. Rasmussen, P. Wiberg-Larsen, A. Baattrup-Pedersen et al., "The legacy of pesticide pollution: An overlooked factor in current risk assessments of freshwater systems," Water Research, vol. 84, pp. 25-32, 2015.
[3] I. Mnif and D. Ghribi, "Potential of bacterial derived biopesticides in pest management," Crop Protection, vol. 77, pp. 52-64, 2015.

[4] Suhas, V. K. Gupta, P. J. M. Carrott, R. Singh, M. Chaudhary, and S. Kushwaha, "Cellulose: A review as natural, modified and activated carbon adsorbent," Bioresource Technology, vol. 216, pp. 1066-1076, 2016.

[5] S. M. Korotta-Gamage and A. Sathasivan, "A review: Potential and challenges of biologically activated carbon to remove natural organic matter in drinking water purification process," Chemosphere, vol. 167, pp. 120-138, 2017.

[6] A. Bazan-Wozniak, P. Nowicki, and R. Pietrzak, “The influence of activation procedure on the physicochemical and sorption properties of activated carbons prepared from pistachio nutshells for removal of $\mathrm{NO}_{2} / \mathrm{H}_{2} \mathrm{~S}$ gases and dyes," Journal of Cleaner Production, vol. 152, pp. 211-222, 2017.

[7] A. Derylo-Marczewska, M. Blachnio, A. W. Marczewski, A. Swiatkowski, and B. Buczek, "Adsorption of chlorophenoxy pesticides on activated carbon with gradually removed external particle layers," Chemical Engineering Journal, vol. 308, pp. 408418, 2017.

[8] A. Macías-García, M. Gómez Corzo, M. Alfaro Domínguez, M. Alexandre Franco, and J. Martínez Naharro, "Study of the adsorption and electroadsorption process of $\mathrm{Cu}$ (II) ions within thermally and chemically modified activated carbon," Journal of Hazardous Materials, vol. 328, pp. 46-55, 2017.

[9] N. Miriyala, D. Ouyang, Y. Perrie, D. Lowry, and D. J. Kirby, "Activated carbon as a carrier for amorphous drug delivery: Effect of drug characteristics and carrier wettability," European Journal of Pharmaceutics and Biopharmaceutics, vol. 115, pp. 197-205, 2017.

[10] A. Athappan, M. L. Sattler, and S. Sethupathi, "Selective catalytic reduction of nitric oxide over cerium-doped activated carbons," Journal of Environmental Chemical Engineering (JECE), vol. 3, no. 4, pp. 2502-2513, 2015.

[11] R. D. Sjogren and D. R. Sjogren, "Controlled release of pesticides with activated carbon," WO 96/38039, 1996.

[12] C. Sun, H. Cui, Q. Liu et al., "Properties of abamectin delivery system loaded by mesoporous activated carbon," Chinese Journal of Pesticide Science, vol. 12, no. 2, pp. 214-220, 2010.

[13] C. Sun, Y. Wang, H. Cui, and J. Jiang, "Effect of surface modification on mesoporous activated carbon's adsorption capacity to two agro-antibiotics," Chinese Journal of Pesticide Science, vol. 14, no. 1, pp. 89-94, 2012.

[14] L. S. Crouch, "Photodegradation of avermectin Bla thin films on glass," Journal of Agricultural and Food Chemistry, vol. 39, no. 7, pp. 1310-1319, 1991.

[15] K. Y. Foo and B. H. Hameed, "Mesoporous activated carbon from wood sawdust by $\mathrm{K}_{2} \mathrm{CO}_{3}$ activation using microwave heating," Bioresource Technology, vol. 111, pp. 425-432, 2012.

[16] F. Marrakchi, M. Ahmed, W. Khanday, M. Asif, and B. Hameed, "Mesoporous-activated carbon prepared from chitosan flakes via single-step sodium hydroxide activation for the adsorption of methylene blue," International Journal of Biological Macromolecules, vol. 98, pp. 233-239, 2017.

[17] Z. Yue and J. Economy, "Nanoparticle and nanoporous carbon adsorbents for removal of trace organic contaminants from water," Journal of Nanoparticle Research, vol. 7, no. 4-5, pp. 477487, 2005.

[18] I. Langmuir, "The constitution and fundamental properties of solids and liquids, Part I: solids," Journal of the American Chemical Society, vol. 38, no. 2, pp. 2221-2295, 1916. 
[19] I. Langmuir, "The constitution and fundamental properties of solids and liquids. II. Liquids," Journal of the American Chemical Society, vol. 39, no. 9, pp. 1848-1906, 1917.

[20] H. Freundlich, "Over the adsorption in solution," The Journal of Physical Chemistry C, vol. 57, pp. 385-470, 1906. 


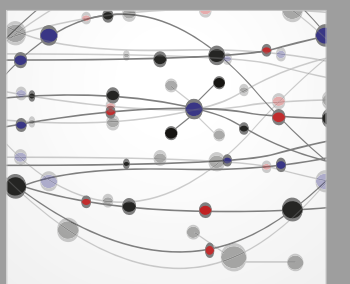

The Scientific World Journal
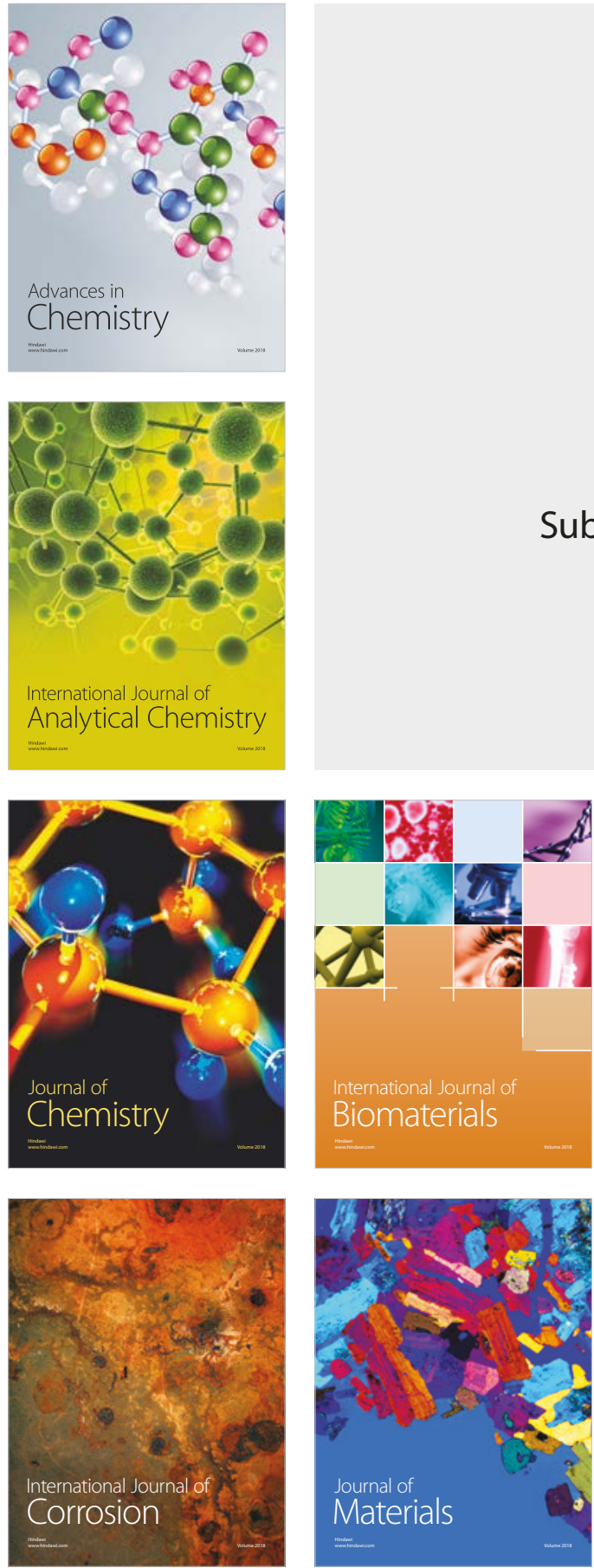

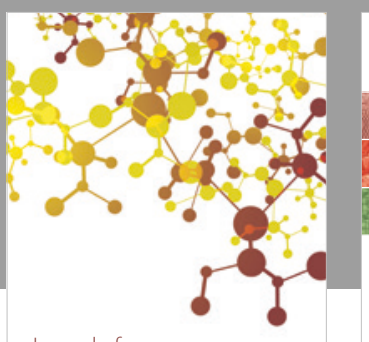

Journal of

Applied Chemistry
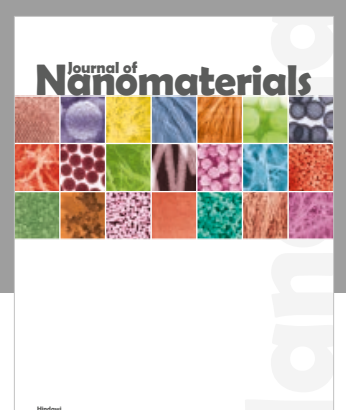

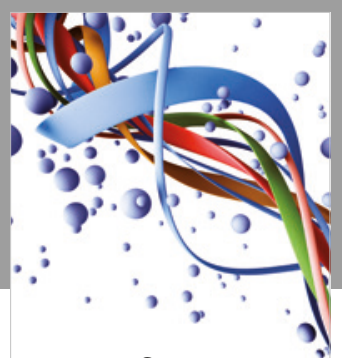

Scientifica

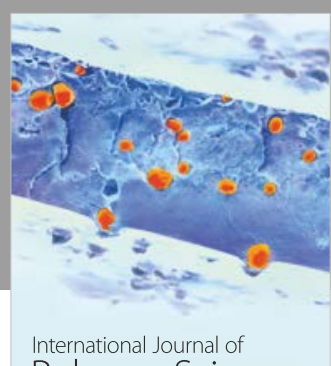

Polymer Science

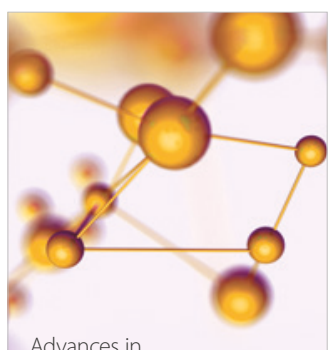

Physical Chemistry
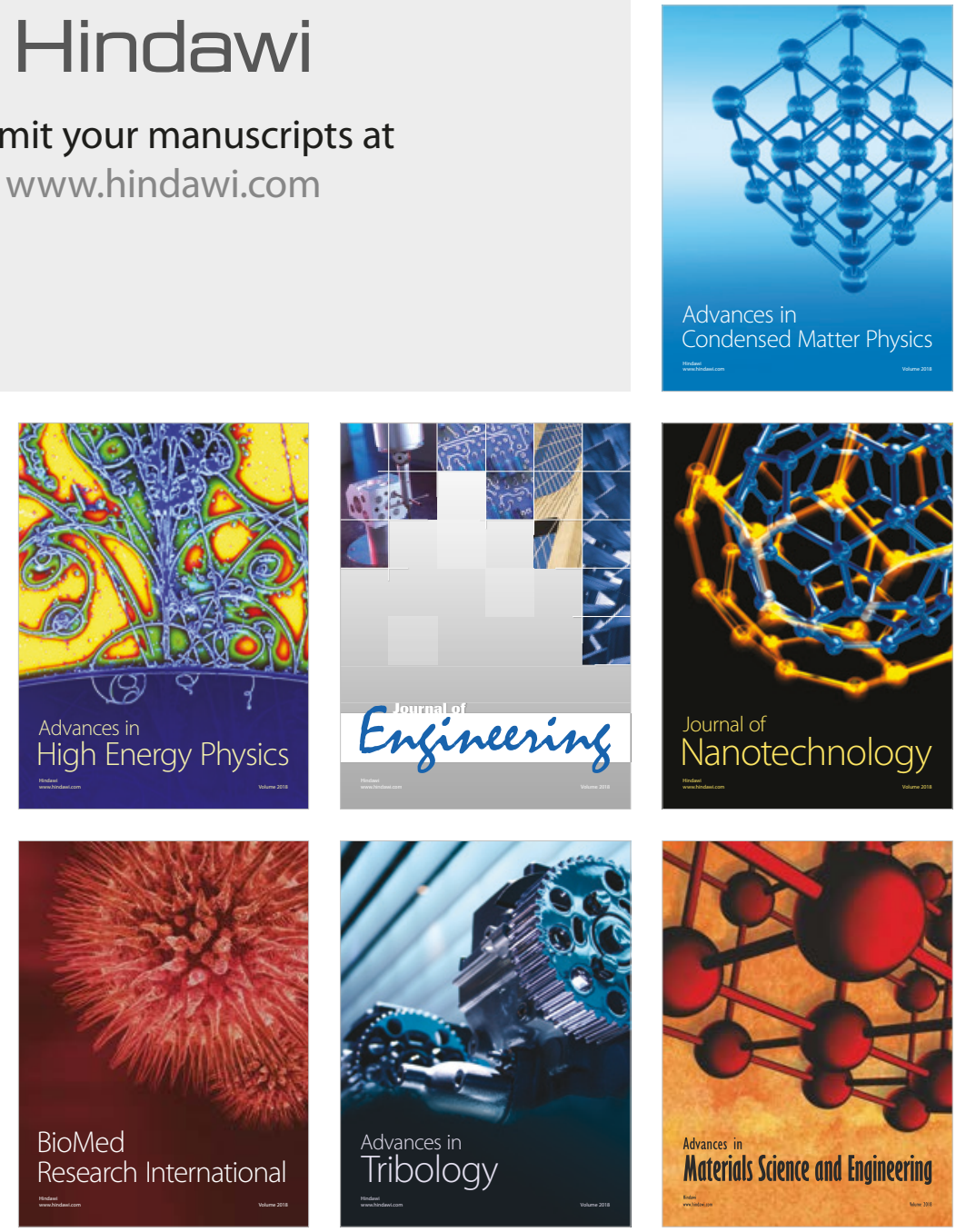